\title{
Parenting Styles as a Predictor of Academic Achievement of Junior High School Students in Aowin and Suaman District, Ghana
}

\author{
David Baidoo-Anu $^{1 *} \quad$ Perpetual Abiaw ${ }^{1} \quad$ Rebecca Kaedebi-Donkor ${ }^{2}$ \\ 1.Department of Education and Psychology, University of Cape Coast, Ghana \\ 2. College of Distance Education, University of Cape Coast, Ghana
}

\begin{abstract}
The study examined the relationship between parenting styles and academic achievement of Junior High School students in the Aowin and Suaman District's in the Western Region of Ghana. To achieve this, a descriptive design was adopted. A sample size of 400 Junior High School students were selected for the study using proportional allocation. Questionnaires were used to elicit responses from selected students coupled with their test scores. The data were analysed using inferential statistics (multiple regression and Pearson product moment correlation) and descriptive statistics (means and standard deviation). The findings from the study revealed that parenting styles correlate high with academic achievement and as such parenting styles have relationship with the academic achievement of students. Several recommendations were offered which include the fact that community and all the structures within it including schools, community heads, churches and media must help in ensuring that parents are more responsible towards their children.
\end{abstract}

Keywords: Parenting styles, Academic achievement, Junior High School, Students

DOI: $10.7176 / \mathrm{JEP} / 10-19-06$

Publication date:July $31^{\text {st }} 2019$

\section{Introduction}

Children academic achievement is largely influenced and determined by the nature of parenting styles and the kind of support parents give to their children (Hofer, 2010). Waters, Carr, Kefalas and Holdaway (2011) indicated that there is a significant relationship between parenting styles and parental support. Researchers asserted that parenting styles determined the level of parental support that parents provide for their children (Lareau, 2011). Family environment created by a particular parenting style may determine the level of parental support which may also have a relationship with one's academic achievement (Sheldon \& Epstein, 2005). These results infer that the process of students' academic achievement and growth is based on the creation of reports and agreements between the parent and the child, where parents in most cases decide the best way to treat a child, and thereby maintaining a balance between freedom and coercion (Jeynes, 2007).

Previous studies have shown that parents, through their parenting styles built critical foundations for various aspects of their children's development and achievement (Roche, Ensminger \& Cherlin, 2007; Jeynes, 2011). Jacobs and Harvey (2005) indicated that parenting style is one of the significant contributors to student's academic achievement in school. Previous studies has established relationships between parenting styles and the academic achievement of students in all levels (Blondal \& Adalbjarnardottir, 2009; Bigner, 2010). Other researchers found inconsistent results. For example, Joshi, Ferris, Otto and Regan (2003) found that there is no significant relationship between parenting styles and college students' grade point average.

Ineffective or inadequate parental assistance may lead a child to feel overwhelmed and consequently withdraw from school. Parental support is one factor that has been consistently related to a child's increased academic achievement (Turner, Chandler, \& Heffer, 2009). The literature on academic achievement among children suggests that children's academic achievement improve when both parents are actively involved in their education (Nyarko, 2011). Alsheikh, Parameswaran and Elhoweris (2010) concurs that greater parental support and involvement at an early stage in children's learning, positively affects the children's school achievement.

\section{Statement of the Problem}

In Ghana, researchers showed that parents worry about the affairs of their children's school environment (Nyarko, 2011; Chowa, Ansong, \& Osei-Akoto, 2012). For this reason, Nyarko (2011) further argues that Ghanaian parents often help mostly on a limited basis towards ensuring completion of their children's homework. Studies found that parental involvement is positively associated with students' academic achievement in school (Nyarko, 2011).

In fact, a number of factors such as school-related factors, teacher-related factors, home-related factors and student-related factors has been identified as contributing to the poor achievement of students' in West Africa Senior Secondary Certificate Examination (WASSCE) in Ghana (Adane, 2013). This has become a recurrent phenomenon which has militated against the smooth transition from the secondary level to the tertiary level. The 
problem is so alarming that it has become necessary for students to pass certain required subjects before one can be admitted into tertiary institutions to pursue a particular programme (Donkor, 2010).

There appears to be little research available on the relationship between of parenting styles and academic achievement of JHS students in Ghana especially in Aowin and Suaman District in the Western Region of Ghana. Most of the studies in Ghana looked at single parenting and a few looked at parenting styles and its effect on students' academic achievement at the basic level (Donkor, 2010; Nyarko, 2011; Chowa et al., 2012; Abudu \& Fuseini, 2013). However, this study seeks to investigate the relationship between parenting styles and academic achievement of JHS students. Equally, this study is timely as the achievement s of students' at the JHS levels are declining in recent times (WAEC, chief examiner report, 2015).

\section{Purpose of the Study}

The main purpose of the study was to investigate the relationship between parenting styles and academic achievement of JHS students in Aowin and Suaman Districts in the Western Region of Ghana. Specifically, the study sought to

1. assess the relationship between parenting styles and academic achievement of JHS students in the Aowin and Suaman Districts in the Western Region

2. Find out which of the parental styles best influence the academic achievement of JHS students in the Aowin and Suaman District in the Western Region.

\section{Research Questions}

The following research questions were formulated to guide the study.

1. What is the relationship between parenting styles and academic achievement of JHS students in the Aowin and Suaman District's in the Western Region?

2. Which of the parental styles best influence the academic achievement of JHS students in the Aowin and Suaman District in the Western Region?

\section{LITERATURE REVIEW}

\section{The Concept of Parenting Styles}

Parenting styles are beneficial in understanding complex behaviours and attitudes associated with children's achievement (Rodriguez, Donovick, \& Crowley, 2009). Parenting is parental behaviours which encompass pleasures, privileges, and profits as well as frustrations, fears, and failures. Thus, parents can find an interest and derive considerable and continuing pleasure in their relationships and activities with their children (Dawkins, 2006).

There are nine parenting styles that were suggested by Baumrind (1991). These are; authoritative, demanding, traditional, authoritarian, undifferentiated, democratic, permissive, nondirective, and rejectingneglecting. However, current researchers have found out that parenting styles are often adapted by previous generations (Brown and Iyengar, 2008) and are passed down by culture.

Parenting style is one of the variables that have been studied extensively in human development (Baldwin, Mclntyre, \& Hardaway, 2007). It is considered an important determinant of several aspects of children's outcome (Gadeyne, Ghesquiere, \& Onghena, 2004). The notion has been related to children and adolescent academic achievement, optimism, confidence, motivation, externalising problem behaviour and attention problems (Gadeyne, Ghesquiere, \& Onghena, 2004). Moreover, parenting style depends on the behavior and attitude of parents. Two major variables identified by Baumrind (1991) centered on parenting styles and child outcomes. One of them was the responsiveness of parents to their child's needs in a reasonable, nurturing and supportive way.

It is generally agreed that parenting style influences self-efficacy, self-esteem, and identity development, which are associated with academic achievement (Brown \& Iyengar, 2008). In addition, the progress in children's achievement is influenced by the decision that is made by both parents and their children to cooperate or confront each other. Furthermore, children's academic motivation and behaviour are directly influenced by family activities and parents' behaviour, which are seen as the external factor. For instance, there is a positive outcome for both parents and children when parents interact in a fun and loving way during children's homework time (Morawska, 2007).

Conversely, when parents are neglectful, academic disengagement and problem behaviour are generated (Brown \& Iyengar, 2008). According to Skowron, (2005) mothers who were better in modulating emotion and ability had children who had higher scores for verbal and math achievement. Further, parents are seen to communicate their characteristics or explanations for their children's achievement in terms of day-to-day interactions and behaviour with their children (Phillipson, 2007). Phillipson (2007) stated children's achievement is influenced by their parents attitudes.

The foundation for parenting style and academic achievement is formed by the belief systems and attitudes 
of parents and their children (Brown \& Iyengar, 2008). For example, Pastorelli et al. (2001) found that children with authoritarian parents perceived themselves as less efficacious for self-directed learning. In general, children are enhanced by authoritative parents and show higher academic competence, social development, selfperception, and mental health compared to children with authoritarian and permissive parents (Baumrind, 2012)

Children's self-concepts at home or at school are influenced by parents' views, whether positive or negative, and can be an important factor for academic achievement (Sarason, Pierce, Bannerman, \& Sarason, 1993). For instance, a study conducted on mathematics achievement in China and the United States showed that American children believed that they were making appropriate progress in school even if they were not. This notion was consistent with their parents' expression of high satisfaction with their children's advance of academic ability. In contrast, Salili, Chiu, and Hong, (2001) found that Chinese parents placed a high value on effort rather than ability to make sure their children had high academic achievement and they also indicated higher expectations for their children's academic achievement .

Whether parents practice democratic decision making with their children, which can be defined as engagement in cooperative discussion prior to decision making, is a criterion that is commonly used to measure parenting style. Authoritative parents tend to engage in discussions with their child before a more or less joint decision is rendered. Authoritarian and permissive parents, however, tend not to engage in discussions. Instead, unilateral decisions are the norm, with authoritarian parents and children of permissive parents making the decisions. However, most families are not completely democratic or undemocratic decision makers. Thus, this dimension is best measured as a continuum of authoritativeness (Morawska, 2007).

Parenting is a complex activity that consists of much specific behaviours that work individually and together to influence child outcomes. Baumrind (2005) defines parenting style as standards and demands set by parents for their children and this include their responses to and communication with their children. Berk (2006) defines parenting styles as psychological constructs representing standard strategies that parents use in their child rearing. She further defines child-rearing styles as combinations of parenting behaviours that occur over a wide range of situations, creating an enduring child-rearing climate. According to Baumrind (1991), different parents employ different strategies in bringing up their children. She identifies three features that distinguish effective parenting styles from less effective parenting styles. They are acceptance and involvement, control and autonomy granting.

Acceptance of the child and involvement in the child's life help to establish an emotional connection between the child and the parent. Control helps to promote mature behaviour in the child while autonomy granting encourages self-reliance (Hart, Newell \& Olsen, 2003). Baumrind's parenting style typologies were based on two dimensions-'responsiveness' and 'demandingness' (Areepattamannil, 2010). Parental responsiveness (parental warmth or supportiveness) refers to the extent to which parents deliberately foster individuality, self-regulation, and self-assertion by being attuned, supportive, and acquiescent to children's special needs and demands (Baumrind, 2010). Demandingness refers to the level of parental expectations placed on children with regard to behaviour regulation and maturity. Thus, parental demandingness referred to as behavioural control refers to the claims parents make on children to become integrated into the family whole, by their maturity demands, supervision, disciplinary efforts and willingness to confront the child who disobeys (Baumrind, 2010).

\section{Forms/Types of Parenting Styles}

Baumrind (2010) defined four specific child-rearing practices and their consequences for children. These are authoritative, authoritarian, and permissive and neglect styles of parenting based on levels of warmth and control used by the parent in disciplining the child. These are explained below:

\section{Authoritative Parenting Style}

Authoritative parents are warm, responsive, demanding and involved with their children. They set clear limits for their children, but they also show the children respect and allow them to be independent. Parents using this style set high but realistic goals for their children and provide them with support to reach those goals (Keshavarz \& Baharudin, 2009). Authoritative parents establish and impose moral rules for children to follow but support parental authority with justification and explanation for why rules are imposed (Baumrind, 2010). According to Baumrind, authoritative parenting style is the most successful approach to child-rearing. These parents are warm, attentive, and sensitive to their children's needs. Berk (2006) argues that authoritative parents normally establish enjoyable, emotionally fulfilling parent-child relationships that draw children into close connection with their parents.

The mixed balance between parental warmth and strictness summarises the general attitude belonging to authoritative parents. This democratic approach acknowledges the child's need for both discipline and individuality, promoting an open relationship where problems can be discussed and resolved together as a team (Tiller, Garrison \& Block, 2003). Authoritative parents often hold high expectations for their children but, unlike 
the authoritarian style, the children are consistently encouraged along the way. Researchers have suggested that authoritativeness holds the central trio in good parenting-warmth, control and democracy (Steinberg, 2002). It explains why it is often deemed as the most successful parenting style for student achievement.

The success of authoritative parenting is most notable in the various behavioural indicators exhibited by their children. Students of authoritative parents have shown such values as a "stronger work orientation, greater engagement in classroom activities, higher educational aspirations, more positive feelings about school, greater time spent on homework, more positive academic self-conceptions, and lower levels of school misconduct, such as cheating or copying" (Steinberg, 2002, p 6). Therefore, the supportiveness and encouragement employed within the authoritative parenting style eventually provides children with a sense of initiative and confidence in relation to learning (Rogers, Theule, Ryan, Adams, \& Keating, 2009), paving the way for academic success.

Authoritative parenting has often been found to be positively associated with higher achievement. Several studies have suggested that children raised by authoritative parents are usually better achievers than their peers in school (Steinberg, 2002). Whilst the use of parental monitoring is beneficial to children's learning progress, authoritativeness differs from the authoritarian style in that encouragement is used simultaneously to produce a more positive impact on children's achievement. This indicates that "rewarding learning-related behaviours with encouragement and praise" (Areepattamannil, 2010, p4), and not ignored or punished for doing otherwise, can lead to higher achievement in school (Areepattamannil, 2010). Furthermore, authoritative parents provide a balance between affection and support and appropriate degree of parental control.

Ngwiri (2008) equates authoritative parenting style to democratic style. This is because these parents discuss with their children why a certain behaviour is desirable. Boveja (2008) has suggested that since children of authoritative parents are more enthusiastic about school, they are often found engaging in more effective learning strategies, and will thus more likely work toward higher academic results. Therefore, when compared with other styles, children of authoritative parents tend to be higher academic achievers.

Authoritative parents have high demandingness and high or medium responsiveness (Baumrind, 1991). Moreover, authoritative parents reasonably attempt to direct their children's activities and use more warm control, positivity during communication, feelings-oriented reasoning as well as induction, and more responsiveness to children's questions (Mize \& Pettit, 1997). Interestingly, adolescents with authoritative parents reported higher grades in school achievement than adolescents with neglectful parents, and demonstrated stronger school orientation, school engagement, and bonding with teachers than adolescents with neglectful parents (Steinberg, Eisengart, \& Cauffman, 2006). Demanding parents are medium responsive and high demanding (Baumrind, 1999). However, traditional parents exhibited a different structural role between mothers and fathers. For example, mothers are highly responsive however, relatively understanding. In contrast, fathers are highly demanding, but quite coercive and non-responsive.

Advantages of authoritative parenting may differ depending on the particular ethnic groups. For instance, European American, African American, Asian American, and Hispanic American were compared by Steinberg et al. (1992) in order to look at the influence between parenting styles and academic achievement for adolescents. The findings revealed that European American, African American, and Hispanic American adolescents' higher school achievement was significantly predicted by authoritative parenting, but this was not the case for Asian American adolescents. In addition, Steinberg, Lamborn, Dornbush and Darling (1992) found that the parents of European American adolescents were most likely to use authoritative parenting. In contrast, Asian American adolescents' parents were the least likely to use authoritative parenting. In the western cultures, authoritative parenting produces benefits of higher academic achievement for adolescents. By contrast, in Asian cultures, nonauthoritative parenting is expected to be related to higher school achievement for adolescents Steinberg et al. (1992).

\section{Authoritarian Parenting Style}

Parents in the restrictive pattern of parenting are identified as authoritarian. Parents in this type attempt to sharpen, control, and evaluate the behaviour and attitude of their children which is usually formulated by a higher secular authority (Baumrind, 1991). These parents are high on demandingness and low on responsiveness (Maccoby \& Martin, 1983). Additionally, children and adolescents with authoritarian parents were reported as having low self-esteem and spontaneity, as well as withdrawal, antisocial, and delinquent behaviors (Coie \& Dodge, 1998). Parents in this pattern value obedience as a virtue and are punitive and forceful (Baumrind, 1991). In contrast, authoritarian parents are strict, do not encourage interpersonal dialogue and exercise absolute control over their children's behaviour according to a rigid set of standards. Baumrind et al (2010) describe authoritarian parents as those who engage in coercive disciplinary practices. These practices include; unqualified power assertion, arbitrary discipline, psychological control, severe punishment and hostile verbal criticism. They demand complete obedience, and in the process do not show much warmth toward their children. Authoritarian parents are characterised by a strict and rigid disciplinary approach and expect obedience without question.

Authoritarian parents are controlling and demanding (Pong, Hao, \& Gardner, 2005). They expect obedience 
from their children and assert power when their children misbehave (Spera, 2005). Authoritarian parents express what they want from their children through rules and orders, and do not communicate to their children the reason behind these rules.

Authoritarian parenting follows a rather dictatorial style involving the highest degree of control on children and very low levels of warmth. Parents who adopt such styles expect strong obedience from their children and favour punitive discipline in response to acts of rebellion (Kang \& Moore, 2011). They are usually found setting strict rules to abide by and monitoring their child's time as well as their activities during the day and night (Areepattamannil, 2010). Moreover, the use of this authoritarian style precludes effective discussion, of any sort, between parents and children, which places more pressure on the children than any other parenting style.

Authoritarian parenting is believed to have adverse effects on children's psychological development. Empirical studies showed that children with authoritarian parents tended to exhibit anxious and withdrawn behaviours, lack self-reliance and rely on authority figures to make decisions diminishing their sense of personal value and responsibility (Baumrind, 2010; Kang \& Moore, 2011). Stress and anxiety in children may experience higher if their authoritarian parents are involved in their academic activities. Additionally, the high level of parental pressure incorporated within the authoritarian style can often reduce children's intrinsic motivation, causing them to be reliant on extrinsic sources, thus undermining the process of learning (Grolnick, 2003). These types of behaviours often trigger poor communication skills (Verenikina, Vialle \& Lysaght, 2011), an essential component predictor of future success.

Owing to the characteristic high level of control over children involved in the authoritarian style, numerous studies have found this parenting style to be negatively associated with academic achievement (Dornbusch, Ritter, Leiderman, Roberts, \& Fraleigh, 2007). A large body of research has documented that parental monitoring is related to lower academic achievement (Rogers, 2009). In fact, Brown and Iyengar (2008) have found that this overemphasis may, in fact, alienate children. Placing excessive pressure on children and interfering with their studies may lead to children having lower academic competence and, consequently, lower academic achievement (Rogers, 2009). Children of authoritarian parents often show poor academic achievement (Attaway \& Bry, 2004). These characteristics negatively affect the child's academic achievement.

A study conducted by Roberts, and Fraleigh (1997) indicated that authoritative parenting positively related to grades; conversely, both authoritarian and permissive parenting negatively related to grades. However, authoritarian parenting is inclined to have a stronger relationship with grades rather than the other two parenting styles. This is because authoritarian parenting tends to be characterized by power.

The findings of a study conducted in Ethiopia documented that an authoritarian parenting style was the most commonly practiced parenting style since socio-political system adhered to authoritarianism in every realm of human endeavours. On the other hand, a likely reason for the findings of the studies in the last two decades which reported that an authoritative parenting style was the most predominantly employed parenting style could be, as noted by numerous researchers (Seleshi, 1998).

Ethiopian parents for example attach very high values to their children in the hope that they will provide social, economic, and psychological support for their parents especially when they become older, and to ensure the continuity of family lineage. Another possible explanation could be that the rapid socio-political changes that have been induced in the country in the drive for modernization and globalization may have resulted in some cultural changes including child-rearing practices. This is why some investigators affirmed that a change in the socio-political system is accompanied by cultural changes (Mapes, 2008). For these reasons, parents may employ more accepting, firm, and democratic child rearing practices which is authoritative parenting style.

\section{Permissive Parenting Style}

Parents who are permissive are described as warm, responsive and have high nurturing abilities but lack parental control and expect few mature behaviours from their children. Permissive parents are lenient towards their children's impulses, desires and actions. These parents have few demands and allow their children do whatever they want (Baumrind, 2010; Berk, 2006). Permissive parents are high on parental responsiveness but low on demandingness. Tolerance, warmth, and acceptance are characteristics of these parents although they do not exert authority or great control over their children in terms of enforcing rules (Baumrind, 2005). They make few or no demands for responsibility and orderly behaviour (Baumrind, 2005).

Permissive parents are indulgent and passive in their parenting, and demonstrate love to their children by giving in to the demands of their children. The permissive parent is low on rules and control, but strong on love and affection. These parents tend to spoil their children by allowing them to do as they like. They are quick to forgive, even where this may not be necessary (Roche, Ensminger \& Cherlin, 2007). Parents in this category have the feeling that showing and giving their children love is their ultimate goal in parenting and they are generally very lenient.

The parents are responsive and require some level of responsibility and conduct from the children. They allow the children much freedom with the intention of not wanting to offend the children. Permissive parents 
believe that their children should be free to make their choices of life and most of the children become selfish in the process (Leow \& Chan, 2011). Some parents are seen to be over-committed and over-protective about their children giving rise to the children losing the opportunity of self-confidence, independence, peer-interactions and initiative development in order to prepare for the future (Richmond \& Stocker, 2008).

The children from permissive parents have good self-esteem and better social skills than their peers from other parenting styles, but lack academic motivation. No child is supposed to be over protected if a child is to be socially and academically well trained and directed. Children from permissive parenting style always find it difficult to be independent and responsible and may feel insecure due to lack of boundaries and guidance (Cherry, 2012). The researcher noticed from several literatures that permissive parents produce children that cannot learn from their mistakes and their troubles. Children who are raised by parents who use this particular parenting style have high involvement in delinquency and low psychological functioning (Kim \& Chung, 2003). When compared with academic success, this parenting style is seen as unsuccessful because it does not allow children to develop the self-direct abilities they need to be successful in school (Keshavarz \& Baharudin, 2009). Permissive parents allow their children to regulate their own activities, exert no control and rarely use punishment in children's upbringing. Permissive style negatively impacts children's academic involvement, resulting in their low academic achievement. These parents may not ever visit the school or the classrooms of their children or speak with a school adult involved with their children's educational experience (Baumrind, 2010, 2005). Children reared by permissive parents tend to be less self-reliant and less tolerant of frustration (Kang \& Moore, 2011). They are so familiar with their wants being met at home that they expect everyone else to treat them the same way. In addition, children raised by permissive parents are less likely to be intrinsically motivated, thus lacking persistence in approaching learning tasks (Kang \& Moore, 2011). Ultimately, their lack of self-control often causes difficulties when engaging in social interaction (Brown and Iyengar, 2008), and they may even go so far as to being the school bullies or, ironically, victims of bullying from other children.

Permissive parenting has a tendency to lead children toward lower academic achievement s. Baumrind (1991) and Baumrind, (2010) found that permissive parenting is negatively associated with higher academic achievement, which is most likely the result of the parents' lack of control and discipline over their children. The majority of young children, if left to choose between work and play, are likely to choose play. Consequently, the permissive parent's non-punitive and accepting approach toward their children's desires (does not assist the children in building an appropriate educational foundation but, rather, harms their potential for academic success (Baumrind, 2005).

\section{Neglectful or Uninvolved Parenting Style}

The uninvolved parenting style is predominantly characterised by low levels of both warmth and control. The parent is neither demanding nor responsive Neglectful parenting is also called uninvolved, detached, dismissive or hands-off parenting. The parents are low in warmth, control and are generally not involved in their child's life. Neglectful child rearing practices are disengaging, undemanding, low in responsiveness, and do not set limits (Baumrind, 2005; Berk 2006). Neglectful parenting can also mean dismissing the children's emotions and opinions. Parents are emotionally unsupportive of their children, but will still provide their basic needs. This often reflects the parents' emotional detachment from the children as they are often seen responding only to their children's needs out of annoyance rather than compassion and would otherwise be completely unresponsive (Tiller, Garrison \& Block, 2003).

Neglectful parenting style is characterised by few demands, low responsiveness and little communication. While these parents fulfill the child's basic needs, they are generally detached from their child's life. In extreme cases, these parents may even reject or neglect the needs of their children (Baumrind, 1991). Parents who practice neglectful parenting styles are exemplified in rejecting-neglecting and non-directive parents. By contrast, non-directive parents are low demanding and medium responsive (Baumrind, 1991) while rejecting-neglecting parents are low relative to both demandingness and responsiveness and are unlikely to take part in their children's activities. Interestingly, Ehnval and Parker (2008) found that female depressed patients who underwent rejected or neglected parenting in their childhood had a higher chance of attempting suicide at least once during their lifetime. In contrast, males who had rejected or neglected experiences in their childhood were not as at risk of suicide attempts.

A study by Kassahun (2010) found the predominance of neglectful parenting style for high school aged males, since when males enter high school the parents believe that their sons can manage themselves, and thus they reduce their control as well as their close relationships. Neglectful parenting style tend to display low levels of demandingness since they ask and expect very little of their children. For instance, they rarely assign their children chores. These parents also display low levels of responsiveness to their children. They tend to be relatively uninvolved in their children's lives. As a result, these parents tend to grant their children a very high degree of freedom to do as they wish. In addition, these parents tend not to be very communicative with their children. The child outcomes associated with the neglectful style of parenting are somewhat predictable. In 
general, these children tend to display poor social skills (Constanzo, 1985).

The relative lack of social interactions with adults at home does little to prepare them for social interactions outside the home. On the other hand, they tend to come across as emotionally needy. That is, these children appear to seek emotional guidance and reassurance from others, especially in their close relationships. This is consistent with a tendency of these children to display moderately low levels of self-esteem. This makes them somewhat vulnerable to others who may try to take advantage of them. Unlike the children of authoritarian or tough love parents, their verbal skills and initiative tend to remain intact, though not as good as children of authoritative parents. However, these children often display difficulties with self-discipline, in part for lack of practice. This discipline issues finally translates in the child's academic achievement and therefore display poor results as compared to children in authoritarian and authoritative parenting styles (Morawska, 2007).

Neglectful parenting can stem from a variety of reasons, which include the parents prioritising themselves, lack of encouragement on the parent's part, financial stresses, lack of support and addiction to harmful substances. Children whose parents are neglectful develop the sense that other aspects of the parent's lives are more important than they are. Many children of this parenting style often attempt to provide for themselves or halt depending on the parent to get a feeling of being independent and mature beyond their years (Baumrind, 2010). Parents, and their children, often display contradictory behaviour. Children become emotionally withdrawn from social situations. This disturbed attachment also impacts relationships later on in life. In adolescence, they may show patterns of truancy and delinquency. The neglectful parent usually lacks honour for the children and makes them feel unwanted, angry and left out (Berk, 2006).

The neglectful parent is usually low on rules and love and affection as (Maunganidze \& Latif, 2001). They leave children alone as much as possible, and will not be bothered, unless there is a crisis. This type of parent usually make promises but do not keep them. This makes the children distrust them, and that is a serious failure on the part of a parent. Combined with the attributes of the dominant parent, this parent can be more damaging to children. The balanced parent is the one who knows and clearly defines the rules and the limits as well as informs the children of them. He or she loves and honours the children, demonstrates love and affection, while at the same time insists on good behaviour. They do not trade rules for love, or vice versa, but treat children with respect as human beings with likes and dislikes of their own (Baumrind, 2010; Kang \& Moore, 2011).

Consequently, children of uninvolved parents might be seen with a lack of direction in everyday life. Since uninvolved parents do not provide the necessary attention for their children's needs, the children may likely engage in socially unacceptable behaviour within and outside of school, as they attempt to seek this attention. Engaged in such activities, and with the absence of expectations from others, they may not have the necessary motivation for educational pursuits. It is thus essential that children of this parenting style, and their parents, are sought out, in order to provide appropriate supportive measures, such as counselling services, to assist and guide them in obtaining a direction in life. However, as indicated before, little is known about this style owing to the uninvolved approach, thus, more research needs to be conducted (Areepattamannil, 2010).

\section{RESEARCH METHODOLOGY}

The study employed descriptive survey design. This design was appropriate per this study because it is recommended by Amin (2005) for studies which involve a cross section of respondents or subjects with almost similar characteristics. The researcher collected information from a cross-section of respondents (students) at once without repetitively visiting them. That is to say, the cross-sectional design was most appropriate on big population as mine as it saved time and finances (Creswell, 2003).

Population

The population for the study was JHS students in the Aowin and Suaman Districts in the Western Region. The district has a total of 12 public JHS (Education Monitoring Information Systems- Ghana Education Service [EMIS-GES], 2016). The total number of final JHS students in the 12 schools were 1583 (District Directorate of Education, 2016). Final year (Form 2) students were chosen because they had successfully completed at least two years of their programme.

The sample frame for the study was all second year JHS students in Aowin and Suaman Districts of Western Region. The sample size of 387 students were determined and selected for the study using Krejcie and Morgan (1970) sampling table. According to the table, a population of 1583 gives a sample size of 372 , however this 372-sample size was the minimum hence the researchers decided to increase the sample size to 400 in order to avoid sampling error and increase the chance of generalisation (Krejcie \& Morgan, 1970). Fraenkel and Wallen (2009) have also indicated that for descriptive studies, a larger sample size produces desirable results to generalise over the population. Therefore, a sample size of 400 for this study was considered large enough to produce the desired results and allow for generalisation of the findings over the population.

Base on the level of the students in the schools, proportional allocation was used to determine the sample size for each school. With proportionate allocation, the sample size of each level of the students is proportionate to the population size of the level. The student respondents were selected using the simple random sampling 
technique. Students were made to pick either "IN" or "OUT", written on pieces of paper. Those who picked "IN" were selected and they constituted the sample for the study. The simple random technique was use in order to give students equal chance of being selected and it helped to avoid biases in selecting the respondents. This also helped to improve the representativeness of the sample by reducing sampling error (Saunders et al., 2007).

A questionnaire developed by the researcher and students test scores were used for the data collection. Questionnaire was deemed appropriate for this study because it solicited students view on the effects of parenting styles and academic achievement (Fraenkel \& Wallen, 2009). Since the sample involved was relatively large (400 students), questionnaire was deemed the most ideal tool for collecting the data. The questionnaire was the closed ended type. The questionnaire was developed using four a point Likert scale ranging from "strongly disagree to strongly agree" and from "never to always". The research instrument was organised into three sections (A, B, and C). Section 'A' comprised background information items on students which elicited information about the gender of the student. The Section, 'B', constituted 32 items on parenting styles. The responses to each of the items are in a four (4) point Likert scale format ranging from "Strongly Agree (4) to Strongly Disagree" (1). The final section "Section C" constituted 10 items on parental support.

The researchers assessed students' achievement in English, Mathematics and Science. From Basic Education Certificate Examination (BECE) past questions, the researcher constructed twenty-five (25) test items for each of the three subjects. The reason for the selection of the past BECE question was to ensure standardisation of the test. The past BECE question is standardised; therefore using it ensured test standardisation. The students were informed about the test and were told the date and time that the test will be administered, this was done so that they can prepare for the test. The test was administered to students under examination condition a set date and time. The researcher ensured fairness in the test administration. Students had 45 minutes to respond to the test items. All necessary instructions were given and highlighted. Concerning the scoring of the test, the scoring was done in such a way that each correct response attracted four (4) marks. In all, the test was scored over 100 percent. The obtained scores of the students were used as dependent variable, where the independents variables were run against it for the regression.

For the pre-test, the reliability coefficient using chronbach alpha for the students test was 0.63 . Also, the reliability coefficient using chronbach alpha for the parental style subsection of the questionnaire was 0.71 and 0.69 for the parental support subsection. However, the overall pre-test reliability for the questionnaire was 0.75 . Moreover, for the main work, the reliability coefficient using chronbach alpha for the students test was 0.76 . Also, the reliability coefficient using chronbach alpha for the parental style subsection of the questionnaire was 0.77 and 0.74 for the parental support subsection. However, the overall reliability for the questionnaire was 0.80 .

The demographic data of the respondents was analysed using frequency and percentages. Research question one was analysed using Pearson correlation (r). Pearson correlation was used to examine the relationship between parenting styles, and students' academic achievement. Pearson's correlation coefficient (r) was used to measure the strength of the association between the two variables. Research question two was analysed using multiple regression. The multiple regression was used to measure relationship between predictor variables (parenting styles and support) and a criterion variable (students' academic achievement). Thus, the responses to the questionnaire were score as well as the students test. Concerning the scoring of the test, the scoring was done in such a way that each correct response attracted four (4) marks. In all, the test was scored over 100 percent. The obtained scores of the students were used as dependent variable, where the independents variables were run against it for the regression and the correlation. Multiple regression was also used to determine the overall fit (variance explained) of the model and the relative contribution of each of the predictors (parenting styles and support) to the total variance explained in the criterion variable (students' academic achievement ).

\section{RESULTS, DISCUSSION AND CONCLUSION}

This chapter presents the analysis and interpretation of the findings of the study. The analysis and interpretation of data were carried out based on the results of the research questions set for the study. The analysis was based on the $100 \%$ return rate data obtained from 400 students selected for the study. Section A of the questionnaire was designed to elicit the personal information of the students. These demographic data includes the student's gender.

Table 1- Distribution of the Respondents by Gender

\begin{tabular}{lll}
\hline Gender & Freq & Percent \% \\
\hline Male & 205 & 51.3 \\
Female & 195 & 48.7 \\
Total & 400 & 100.0 \\
\hline
\end{tabular}

Source: Field Data.

Table 1 shows that there are 205 males representing 51.3\% and the females were 195 representing $48.7 \%$. This shows that even though the males were more than the females both males and females were adequately represented in the study. 
Research Question One: What is the relationship between parenting styles and academic achievement of JHS students in the Aowin and Suaman Districts in the Western Region?

The main objective of this research question was to find out the relationship between parenting styles and academic achievement of JHS students in the Aowin and Suaman Districts in the Western Region. To achieve this, Pearson product moment correlation was used for the analysis. The results are presented in Table 1. Prior to conducting the Pearson correlaton certain assumptions must be met. This include normality test. The researchers checked for the assumption before conducting the regression test. Figure 1 shows the normality test for the test variables.

Figure 1- Normality Test

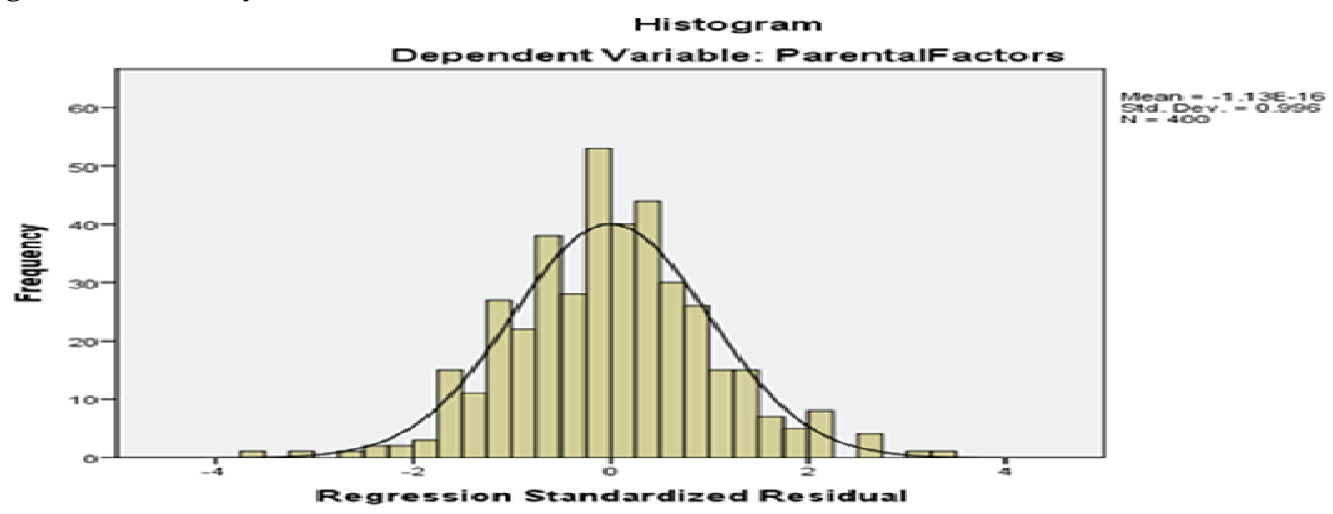

Figure 1 shows that the clustering of the variables were at the centre of the normality curve. This shows that the variables were normal and multiple regression could be performed.

Table 2 therefore shows the descriptive statistics of the study variables.

Table 2- Descriptive statistics of study variables

\begin{tabular}{|c|c|c|c|c|c|}
\hline Variables & Mean & Score range & SD & Skewness & Kurtosis \\
\hline achievement & 42.47 & $0-100$ & 4.41 & -.391 & -.606 \\
\hline Authoritarian & 14.68 & $5-20$ & 1.96 & .064 & -.301 \\
\hline Authoritative & 13.31 & $4-16$ & 1.58 & -.556 & -.207 \\
\hline Neglectful & 28.40 & $11-44$ & 5.28 & .203 & -.509 \\
\hline Permissive & 26.71 & $8-32$ & 1.99 & .192 & -.029 \\
\hline$\underline{\text { Parental support }}$ & 36.95 & $10-40$ & 1.86 & -.162 & .440 \\
\hline
\end{tabular}

The means and standard deviations of the variables and their ranges indicates that achievement with score range of $0-100$ has $(M=42.7$ and $\mathrm{SD}=4.41)$. Authoritarian with score range of 5-20 has $(\mathrm{M}=14.68$ and $\mathrm{SD}=$ 1.96). Authoritative with score range of 13.13 has $(\mathrm{M}=13.31$ and $\mathrm{SD}=1.58)$. Neglectful with score range of 1144 has $(M=28.40$ and $S D=5.28)$. Permissive with score range of $8-32$ has $(M=26.71$ and $S D=1.99)$, Parental support with score range of $10-40$ has $(M=36.95$ and $S D=1.186)$. The skewness and kurtosis values that are close to zero $(0)$ give indication that the data is normally distributed.

Table 3 presents the Pearson product moment correlation coefficient of the relationship between parenting styles and academic achievement of students. Preliminary analyses were performed to ensure that there were no violations of the assumptions of normality, linearity and homoscedasticity.

Table 3-Pearson's Correlation coefficients among study variables

\begin{tabular}{|c|c|c|c|c|c|}
\hline Variable & 1 & 2 & 3 & 4 & 5 \\
\hline 1. achievement & 1 & & & & \\
\hline 2. Authoritarian & $.322^{* *}$ & 1 & & & \\
\hline 3. Authoritative & $.458^{* *}$ & $.241^{* *}$ & 1 & & \\
\hline 4. Neglectful & $-.251^{* *}$ & $.217^{* *}$ & .055 & 1 & \\
\hline 5. Permissive & $.165^{* *}$ & $-.124^{*}$ & $.145^{* *}$ & $.133^{*}$ & 1 \\
\hline
\end{tabular}

*. Correlation is significant at the 0.05 level (2-tailed).

**. Correlation is significant at the 0.01 level (2-tailed).

The results of the table indicates that there is a weak positive correlation between authoritarian parenting style and students' academic achievement $[r=0.322, n=388, p<0.05]$, thus high level authoritarian parenting style goes with high level of students' achievement and vice versa. This result implies that authoritarian parenting style would significantly determine and influence students' academic achievement positively and vice versa. It is concluded that there is a statistically significant relationship between authoritarian parenting style and students' academic achievement, hence, the null hypothesis is rejected. This therefore, suggests that authoritarian parenting style has positive relationship with students' academic achievement . Thus, authoritarian parenting style predicts students' academic achievement in Aowin and Suaman Districts. 
Again, the Table indicates that there is a positive moderate correlation between authoritative parenting style and students' academic achievement $[r=0.458, n=388, p<0.05]$, thus high level authoritative parenting style goes with high level of students' achievement and vice versa. This result implies that authoritative parenting style would significantly determine and influence students' academic achievement positively and vice versa. It is concluded that there is a statistically significant correlation between authoritative parenting style and students' academic achievement, hence, the null hypothesis is rejected. This therefore, suggests that authoritative parenting style has positive relationship with students' academic achievement. Thus, authoritarian parenting style predicts students' academic achievement in Aowin and Suaman Districts.

Furthermore, the Table indicates that there is a negative weak correlation between neglectful parenting style and students' academic achievement $[r=-0.251, n=388, p<0.005]$, thus high level neglectful parenting style goes with low level of students' achievement and vice versa. This result implies that neglectful parenting style would significantly determine and influence students' academic achievement negatively and vice versa. It is concluded that there is a statistically significant correlation between neglectful parenting style and students' academic achievement, hence, the null hypothesis is rejected. This therefore, suggests that authoritative parenting style has negative relationship with students' academic achievement. Thus, neglectful parenting style predicts students' academic achievement in Aowin and Suaman Districts.

Finally, Table 3 shows that there is a positive weak correlation between permissive parenting style and students' academic achievement $[r=0.165, n=388, p<0.05]$, thus high level permissive parenting style goes with high level of students' achievement and vice versa. This result implies that neglectful parenting style would significantly determine and influence students' academic achievement positively and vice versa. It is concluded that there is a statistically significant correlation between neglectful parenting style and students' academic achievement, hence, the null hypothesis is rejected. This therefore, suggests that neglectful parenting style has positive relationship with students' academic achievement. Thus, neglectful parenting style predicts students' academic achievement in Aowin and Suaman Districts.

Research Question Two: Which of the parental styles best influence the academic achievement of JHS students in the Aowin and Suaman District in the Western Region.

To accomplish the purpose of the study, the researcher sought to find which of the parenting styles predict the academic achievement among JHS students in the Aowin and Suaman Districts. To achieve this, multiple regression was deemed appropriate for the analysis. The multiple regression was utilised to show the direction and magnitude of the effects and relationship between parenting styles and parental support and students' academic achievement .

Table 4 presents the results of the multiple regression analysis between independent variables (Authoritarian, Authoritative, Neglectful, Permissive) and the dependent variable (students' academic achievement).

Table 4- Results of the Multiple Regression Analysis of the Parental Factors

\begin{tabular}{|c|c|c|c|c|c|}
\hline \multirow[t]{2}{*}{ Variables } & \multicolumn{2}{|c|}{ Unstandardized Coefficients } & \multirow{2}{*}{$\begin{array}{l}\text { Standardized Coefficients } \\
(\beta)\end{array}$} & \multirow{2}{*}{$\begin{array}{l}\mathrm{t}- \\
\text { value }\end{array}$} & \multirow[t]{2}{*}{ p-value } \\
\hline & $\mathrm{B}$ & Std. Error & & & \\
\hline (Constant) & 6.246 & 4.501 & & 1.388 & .166 \\
\hline Authoritarian & .398 & .104 & .177 & 3.819 & .000 \\
\hline Authoritative & 1.036 & .130 & .372 & 7.976 & .000 \\
\hline Neglectful & .148 & .038 & .177 & 3.907 & .000 \\
\hline Permissive & .119 & .099 & .054 & 1.196 & .233 \\
\hline Multiple R va & \multicolumn{2}{|c|}{$.553 a$} & F value & & 31.870 .000 \\
\hline R Square valu & \multicolumn{2}{|c|}{0.306} & $\mathrm{P}$ value & & 1.752 \\
\hline Adjusted R S & \multicolumn{2}{|c|}{.296} & Durbin-Watson & & \\
\hline
\end{tabular}

a. Predictors: (Constant), Authoritarian, Authoritative, Neglectful, Permissive

b. Dependent Variable: Students' Academic achievement

Source: Field Survey

Dependent Variable: Students achievement *significant at the 0.05 level (2-tailed).

The results of the multiple regression analysis in Table 4 shows that the multiple correlation coefficients is 0.553 and it measures the degree of relationship between the actual values and the predicted values of the students' academic achievement. Because the predicted value is obtained as a linear combination of authoritarian, authoritative, neglectful, permissive, parenting support, the coefficient value of 0.553 indicates that the relationship between independent variables (authoritarian, authoritative, neglectful, permissive) and dependent variable (students' academic achievement) is very moderate and positive.

From Table 4, the R2 (R-square) measures the goodness-of-fit of the estimated Sample Regression Plane (SRP) in terms of the proportion of the variation in the dependent variables explained by the fitted sample 
regression equation. That is, the value of $\mathrm{R}$-square is .306, which simply means that about $30.6 \%$ of the variation in students' academic achievement is explained and accounted for by the predictors as the independent variables and R square value is significant at 5 percent level. The adjusted R2 gives us some idea of how well the model generalises and ideally its value should be same or very close to the value of R2. In this model, the difference is fair a bit .296 or $2.96 \%$ ). This shrinkage $(2.96 \%)$ means that if the model was derived from the population rather than the sample, it would account for approximately $2.96 \%$ less variance in the outcome.

From Table 4, the Durbin-Watson statistics is 1.752 and it tests for auto-correlation in the residuals from a statistical regression analysis Thus, it informs whether the assumption of independent errors is tenable or otherwise and in this data, it is seen that the value is close to 2; hence, the assumption has almost certainly been met. The Durbin-Watson statistics is 1.752 and it is between the two critical values of $1.5<\mathrm{d}<2.5$. Therefore, I can assume that there is no first order linear auto-correlation in the multiple linear regression data, and that there is no auto-correlation in the sample. From the multiple linear regression model, it is again seen that the F-test has the null hypothesis that there is no linear relationship between the variables (in other words, $\mathrm{R}^{2}=0$ ). The value of F-test is found as below the standard value of rule of thumb 4.00 and the significance level is just 0.000 . The Ftest is highly significant. Thus, we can assume that there is a linear relationship between the variables in our model. All these findings are disclosing that the model is satisfactory. All these findings give credence that the model used was satisfactory.

From Table 4, the multiple regression coefficients (b-values) shows the relationship between students' academic achievement and each predictor (independent variables). If the value is positive, then there is a positive relationship between the predictors (independent variables) and the predicted variable (students' academic achievement) whereas a negative co-efficient represents a negative relationship. The multiple regression coefficient also indicates the degree to which each predictor affects the dependent variable if the effect of all other predictors are held constant.

As shown in Table 4, the constant of the regression model was 6.246 which mean that even when the independent variables (authoritarian, authoritative, neglectful, permissive) are held constant or held at zero, students' academic achievement will still be 6.246. The coefficient of authoritarian parenting style is .398, representing the partial effect of authoritarian parenting style on students' academic achievement, and holding other independent variables as constant. The estimated positive sign implies that such effect of authoritarian parenting style on students' academic achievement is positive and that students' academic achievement score would decrease by 0.398 for every unit increase in authoritarian parenting leadership style. Again, the multiple regression coefficients of 1.036 representing the partial effect of authoritative parenting style on students' academic achievement, holding other independent variables as constant. The estimated positive sign implies that such effect of authoritative parenting style on students' academic achievement is positive and that students' academic achievement score would increase by 1.036 for every unit increase authoritative parenting style.

From Table 4, it is again, found that the multiple regression coefficients of neglectful parenting style is .148 representing the partial effect of neglectful parenting style on students' academic achievement, holding other independent variables as constant. The estimated positive sign implies that such effect of neglectful parenting style on students' academic achievement is positive and that students' academic achievement score would increase by .148 for every unit increase in neglectful parenting style. Yet again, the multiple regression coefficients of permissive parenting style is .119, representing the partial effect of permissive parenting style on students' academic achievement, holding other independent variables as constant. The estimated positive sign implies that such effects of permissive parenting style on students' academic achievement is positive and that students' academic achievement score would increase by 0.119 for every unit increase in permissive.

From Table 4, it can be seen that the independent variables (predictors) coefficient value is significant at $5 \%$ level. This means that authoritarian parenting style, authoritative parenting style, neglectful parenting style, permissive parenting style and parenting support are significant variables that determine and predict students' academic achievement. The b-value (co-efficient) has an associated standard error indicating to what degree or extent these values would vary across different samples, and these standard errors were used to determine whether or not the b-values differ significantly from zero using t-statistics). From Table 8 , it is clear that the $t$ test associated with each b-value (co-efficient) is significant (p-value less than 0.05 ) with the exception of permissive parenting style. Therefore, it could be said that each predictor (independent variables) with the exception of permissive parenting style is making a valuable and significant contribution to the model. For this model, authoritarian parenting style, $\mathrm{t}(388)=3.819, \mathrm{p}=0.000$, authoritative parenting style, $\mathrm{t}(388)=7.976$, $\mathrm{p}=0.000$, neglectful parenting style, $\mathrm{t}(388)=3.907, \mathrm{p}=0.000$ and permissive parenting style, $\mathrm{t}(388)=1.196$, $\mathrm{p}=0.233$. From the magnitude of the t-statistic, I can conclude that authoritative parenting style had more impact or effect or prediction of student academic achievement, followed by authoritarian parenting style, neglectful parenting style, and permissive parenting style. Therefore, it is also concluded that there is a significant impact (prediction) of authoritative parenting style, authoritarian parenting style, neglectful parenting style and permissive parenting style on students' academic achievement; consequently, the null hypothesis is rejected. 


\section{DISCUSSIONS}

\section{Parenting Styles and Students' Academic achievement}

The main objectives of the study was to examine the relationship between parenting styles and the academic achievement of JHS students in the Aowin and Suaman Districts in the Western Region. The findings from the study suggest that the parenting styles that parents adopt in the Aowin and Suaman Districts have a relationship with students' academic achievemen. The results from the analysis give reasons to believe that the academic achievement of students in the Aowin and Suaman Districts is dependent on the parenting styles. The findings from the study lends support to the work of Dornbusch et al. (2007) who found that the parenting styles that parents adopts correlated with grades of adolescents.

The findings again support the assertions of Jacobs and Harvey (2005) who claimed that there exists ample evidence in the literature that insinuate that parenting styles correlated with children's school achievement. Jacobs and Harvey (2005) further indicated that parenting style is one of the significant contributors to student's academic achievement in school. Notwithstanding, Tope (2012) indicated that although students are primarily the ones for whom curricula are designed, textbooks are written, and schools built, parents are primarily the ones held responsible for preparing students for learning preparation physically, psychologically, behaviourally, attitudinally, emotionally, and motivationally. According to Tope, without the appropriate parenting style, parental involvement and proactive preparation of the child in the areas mentioned above, the child is likely to perform poorly in school. Tope finding therefore suggests that the type of parenting styles parents adopt have direct relationship with the academic achievement of their children. One of the most robust approaches in the development of children's social and academic achievement has been termed "parenting style" (Turner, Chandler, \& Heffer, 2009). Research on parenting styles has shown that it is related to a variety of outcomes, such as psychological problems and academic outcomes, in the lives of children (Turner, Chandler, \& Heffer, 2009). Parents express their attitudes towards their children by the different parenting style they epitomize and use. The values, behaviours and standards set forth by parents are conveyed to their children through the different parenting styles (Kim \& Chung, 2003).

\section{SUMMARY, CONCLUSIONS AND RECOMMENDATIONS}

The findings from the study revealed that, there is a weak positive correlation between authoritarian parenting style and students' academic achievement $[\mathrm{r}=0.322, \mathrm{n}=388, \mathrm{p}<0.05]$. Again, the results of the study indicated that there is a positive moderate correlation between authoritative parenting style and students' academic achievement $[\mathrm{r}=0.458, \mathrm{n}=388, \mathrm{p}<0.05]$. Furthermore, the results of the study indicated that there is a negative weak correlation between neglectful parenting style and students' academic achievement $[\mathrm{r}=-0.251, \mathrm{n}=388, \mathrm{p}<$ 0.005]. Moreover, the results of the study indicated that there is a positive weak correlation between permissive parenting style and students' academic achievement $[\mathrm{r}=0.165, \mathrm{n}=388, \mathrm{p}<0.05]$.

Finally, the results of the regression analysis showed that there is a moderate positive relationship between independent variables (authoritarian, authoritative, neglectful, permissive, parenting support) and dependent variable (students' academic achievement), $[\mathrm{r}=.553, \mathrm{n}=388]$. It was revealed that there is a significant impact (prediction) of authoritative parenting style, authoritarian parenting style, neglectful parenting style parenting support, permissive parenting style and on students' academic achievement $[\mathrm{n}=388, \mathrm{p}=0.00]$. Again, the study revealed that authoritative parenting style had more impact, or effect, or prediction of student academic achievement, followed by authoritarian parenting style, neglectful parenting style parenting support, and permissive parenting style.

\section{CONCLUSION}

Based on the findings of the study, it is concluded that, the academic achievement of students in the JHS students in the Aowin and Suaman Districts is greatly influenced by the type of parenting styles. The findings from the study gives ample evidence to believe that, the academic achievement of students in the JHS students in the Aowin and Suaman Districts is dependent on the parenting styles in the Aowin and Suaman Districts. However, authoritative parenting style had more impact, or effect, or prediction of student academic achievement , followed by authoritarian parenting style, neglectful parenting style parenting support, and permissive parenting style. Parents in the Aowin and Suaman Districts should be sensitised on the awareness of parenting styles and dimensions of parenting within the Aowin and Suaman Districts in Ghana. This will help parents to adopt the right parenting style to help improve students' academic achievement

\section{References}

Abudu, A. M., \& Fuseini, M. N. (2013). Influence of single parenting on students' academic achievement in basic schools in the Wa Municipality. International Journal of Education Learning and Development, 1(2), $85-94$.

Adalbjarnardottir, S., \& Hafsteinsson, L. G. (2001). Adolescent's perceived parenting styles and their substance 
use: concurrent and longitudinal analyses. Journal of Research on Adolescence, 11(4), 401-423.

Alsheikh, N., Parameswaran, G., \& Elhoweris, H. (2010). Parenting style, self-esteem and student achievement in the United Arab Emirates. Current issues in Education, 13(1), 265-179

Amin, E. M. (2005). Social Science Research Conception Methodology and Analysis. Kampala: Makerere University Printery.

Attaway, N. M., \& Bry, B. H. (2004). Parenting Style and Black Adolescents' Academic Achievement. Journal of Black Psychology, 30(2), 229-247.

Atuahene, A. \& Owusu-Ansah, A. (2013). A Descriptive Assessment of Higher Education Access, Participation, Equity, and Disparity in Ghana. SAGE Open, 3(3), 1-16

Baldwin, D. R., Mclntyre, A., \& Hardaway, E. (2007). Percieved parenting style on students' optimism. American Sociological Review, 56, 309 - 320.

Barnhart, C., Raval, V., Jansari, A., Raval, P. (2013). Perception of parenting style among college students in India and the United States. Journal of Child Family Studies, 2(2), 684-693.

Baumrind, D. (1971). Current patterns of parental authority. Developmental Psychology Monographs, 4(1), 7-8.

Baumrind, D. (1991). The influence of parenting style on adolescent competence and substance use. Journal of Early Adolescence, 11, 56-95.

Baumrind, D. (2005). Patterns of parental authority and adolescent autonomy. New Directions for Child and Adolescent Development, 10(8), 61-69.

Baumrind, D. (2010). The authoritative construct and its effects revisited. New directions in authoritative parenting: Building on the legacy of Diana Baumrind. Symposium Oklahoma State University-Tulsa, Chautauqua on Parenting, Tulsa, OK.

Baumrind, D. (2012). Differentiating between confrontive and coercive kinds of parental power-assertive disciplinary practices. Human Development, 55(2), 35-51.

Berk, L. E. (2006). Child development (6 ${ }^{\text {th }}$ ed.) USA: Pearson Education Inc.

Blondal, K. S., \& Adalbjarnardottir, S. (2009). Parenting practices and school dropout: A longitudinal study. Adolescence 4(4), 729-749.

Boardman, G., \& Evans, L. R. (2000). Community support for education: Local change leaders. Community school alliance, Accra, Ghana.

Bowen, G. L., Hopson, L. M., Rose, R. A., Glennie, E. J., (2012). Students’ Perceived

Parental School Behaviour Expectations and Their Academic achievement : A Longitudinal Analysis. Interdisciplinary Journal of Applied Family Studies, Family Relations 61 (April 2012), 175 - 191.

Brown, L., \& Iyengar, S. (2008). Parenting styles: The impact on student achievement. Marriage \& Family Review, 43(1), 14-38.

Chao, R. K. (2001). Extending research on the consequences of parenting style for Chinese Americans and European Americans. Child Development, 7(2), 1832-1843.

Chowa, G., Ansong, D., \& Osei-Akoto, I. (2012). Parental involvement and academic achievement in Ghana. Youth save Research Brief No. 12-42.

Coie J. D., Dodge K. A. (1998) Aggression and antisocial behavior. In: Eisenberg N, Damon W, editors. Handbook of child psychology, Volume 3 (pp. 779-862). Social, emotional, and personality development. New York: Wiley.

Creswell, J. W. (2003). Research design, qualitative, quantitative and mixed methods approaches. ( $2^{\text {nd }}$ ed.). London: Sage.

Donkor, A. K. (2010). Parental Involvement in education in Ghana: The case of a private elementary school. International Journal about Parents in Education, 4(1), 23-38.

Dornbusch, S. M., Ritter, P. L., Leiderman, P. H., Roberts, D. F., \& Fraleigh, M. J. (2007). The relation of parenting style to adolescent achievement . early adolescence. Child Development, 4 (8), 841-851.

Ehnvall, A., Ber, G., Hadzi-Pavlovic, D., \& Malhi, G. (2008). Perception of rejecting and neglectful parenting in childhood relates to lifetime suicide attempts for females-but not for males. Acta Psychiatrica Scandinavica, $117(1), 50-56$.

Endrulat, N. R., Tom, K., Ravitch, K., Wesley, K., \& Merrell, K. W. (2010). Gender differences in positive social emotional functioning. Annual Meeting of the National Association of School Psychologists, 4(4), 510.

Fraenkel, J. R., \& Wallen, N. E. (2009). How to design and evaluate research in education ( $7^{\text {th }}$ ed.). New York: McGraw Hill.

Gadeyne, E., Ghesquiere, P. \& Onghena, P. (2004). Longitudinal relations between parenting and child adjustment in young children. Journal of Clinical and Adolescents Psychology, 33, 347-358.

Hart, C. H., Newell, L. D., \& Olsen, S. F. (2003). Parenting skills and social-communicative competence in childhood. In J. O. Greene \& B. R. Burleson (Eds.), Handbook of communication and social interaction skills (pp. 753-800). Mahwah, NJ: Lawrence Erlbaum Associates. 
Hofer, B. K. (2010). The connected parent: Staying close to your kids college (and beyond) while letting them grow up. New York City, NY: Free Press.

Jacobs, N., \& Harvey. D. (2005). Do parents make a difference to children's academic achievement? Differences between parents of higher and lower achieving students. Educational Studies, 31(4), 431-448.

Jeynes, W. H. (2007). The relationship between parental involvement and urban secondary school student academic achievement: A meta-analysis. Urban Education, 4 (1), 82-110.

Jeynes, W. H. (2011). Parental involvement and academic success. New York, New York: Routledge.

Kang, Y. \& Moore, J. (2011). 'Parenting style and adolescents' school achievement in mainland China'. USChina Education Review, 1, 133-138

Kassahun, H. (2005). The relationship of parenting styles and academic achievement among primary and secondary school students in Debre-Markos town. Unpublished Master's Thesis, Addis Ababa University, Addis Ababa, Ethiopia.

Keshavrz, S., \& Baharudin, R. (2009). Parenting style in collectivist culture of Malaysia. European Journal of Social Sciences. 10(1), 66.

Kochanska, G. (1992). Children's interpersonal influence with mothers and peers. Development Psychology, 28(3), 491-499.

Krejcie, R. V., \& Morgan, D. W. (1970). Table for determining sample size from a given population. Educational and Psychology Measurement Journal 3 (6), 607-610.

Lareau, A. (2011). Unequal childhoods: Class, race and family life (2 ${ }^{\text {nd }}$ ed.). Berkley, CA: University of California Press.

Leow, M. Q. H, \& Chan, W. S. (2011). Factors affecting caregiver burden of terminally ill adults in the home setting - A systematic review. JBI Libr. Syst. Rev. 9, 1883-1916.

Maccoby, E., \& Martin, J. (1983). Socialization in the context of the family: Parent-child interaction. In: Mussen PH, (ed). Handbook of Child Psychology (pp. 1-101). Wiley; New York.

Mapes, R. R. (2008). The socialization of fear of failure in Japan and the United States. The Science and Engineering journal, 69(5-B), 3320.

Mize, J., \& Pettit, G. S. (1997). Mother's social coaching, mother-child relationship style and children's peer competence: Is the medium the message? Child Development, 68(2), 312-332.

Morawska, A. (2007). Concurrent predictors of dysfunctional parenting and maternal confidence: implicational for parenting interventions. Childcare, health and development, 33(6).

Ngwiri, L. N. (2008). Powerful Parenting: What Every Parent Should Know. Nairobi: Queenex Holdings Ltd.

Niggli A., Trautwein U., Schnyder I., Lüdtke O., Neumann M. (2007). Parental homework support can be beneficial, but parental intrusion is detrimental: family background, parental homework supervision, and achievement gains. Psychol. Erzieh. Unterr. 54 1-14.

Nyarko, K. (2010). Parental home involvement: The missing link in adolescents' academic achievement. Educational Research, 1(9), 340-344.

Nyarko, K. (2011). Parental school involvement: The case of Ghana. Journal of Emerging Trends in Educational Research and Policy Studies (JETERAPS), 2(5), 378-381.

Nyarko, K. (2011). The influence of authoritative parenting style on adolescents' academic achievement. American journal of social and management sciences, 2(3), 278-282.

Nyarko, K. (2011). The mediating role of parental home involvement. Journal of Emerging Trends in Educational Research and Policy Studies (JETERAPS), 2(3), 181-185.

Pastorelli, C., Caprara, G. V., Barbaranelli, C., Rola, J., Rozsa, S., \& Bandura, A. (2001). The structure of children's perceived self-efficacy: A cross-national study. European Journal of Psychological Assessment, 17(2), 87-97

Phillipson, S. (2007). Cultural variability in parent and child achievement attributions: A study from Hong Kong. Educational Psychology. Vol. 26(5), 625-642.

Quioch, A. M. L., \& Daoud. A. M. (2006). Dispelling myths about Latino parent participation in schools. Educational Forum, 70, 255-267.

Roberts. D., \& Fraleigh. S. (1997). Role problems and the relationship of achievement motivation to scholastic achievement . Journal of Educational Psychology, 70(6), 950-959

Roche, K. M., Ensminger, M. E., \& Cherlin, A. J. (2007). Parenting style and adolescent outcomes among African and Latino families living in low income. Journal of Family Issue, 11(23), 882-909.

Rodriquez, G., Crowly J., Hadzi-Donovic, D. (2009). The development of a refined measure of dysfunctional parenting and assessment of its relevance in patients with affective disorders. Psychological Medicine, 27(5), 1193-1203.

Rogers, M. A., Theule, J., Ryan, B. A., Adams, G. R. \& Keating, L. (2009). 'Parental involvement and children's school achievement: Evidence for mediating processes'. Canadian Journal of School Psychology, 24 (1), $34-57$. 
Salili, F., Chiu, C.-y., \& Hong, Y.-y. (2001a). The culture and context of learning. In F. Salili, C.-y. Chiu, \& Y.-y. Hong (Eds.), Student motivation: The culture and context of learning (pp. 1-14). New York, NY: Kluwer Academic/Plenum Publishers.

Salili, F., Chiu, C.-y., \& Lai, S. (2001b). The influence of culture and context on students' motivational orientation and achievement . In F. Salili, C.-y. Chiu, \& Y.-y. Hong (Eds.), Student motivation: The culture and context of learning (pp. 221-247). New York, NY: Kluwer Academic/Plenum Publishers.

Seleshi, Z. (1998). An exploratory study of parenting styles among four ethnic groups in urban settings. Ethiopian Journal of Development Research, 20(2), 1-24.

Steinberg, L. (2001). We know some things: Adolescent-parent relationships in retrospect and prospect. Journal of Research on Adolescence, 1(1), 1-19.

Steinberg, L. (2002). Adolescence (6 $6^{\text {th }}$ ed.). Boston, MA: McGraw Hill.

Steinberg, L., Blatt-Eisengart, I., Cauffman, E. (2006). Patterns of competence and adjustment among adolescents from authoritative, indulgent, and neglectful homes: A replication in a sample of serious juvenile offenders. Journal of Research on Adolescence, 1(6), 47-58.

Steinberg, L., Lamborn, S., Dornbush, S., \& Darling, N. (1992). Impact of parenting practices on adolescent achievement: Authoritative parenting, school involvement, and encouragement to succeed. Child Development, 63(5), 1266-1281.

Steinberg, L., Lamborn, S. D., Darling, N., Mounts, N. S., \& Dornbusch, S. M. (1994). Over-time changes in adjustment and competence among adolescents from authoritative, authoritarian, indulgent, and neglectful families. Child Development, 6(5), 754-770.

Stewart, H. T (2007). Influences of parental involvement on the academic achievement of adolescents. Paper presented at the annual conference of the American Psychological Association, Washington, DC.

Tope, O. (2012). The Influence of Parenting Style on the Academic achievement of Students: A Case Study of Some Selected Secondary Schools in Agege Local Government Area of Lagos State. EgoBookster Books, Ogun State, Nigeria

Turner, E. A., Chandler, M., \& Heffer, R. W. (2009). The Influence of Parenting Styles, Achievement Motivation, and Self-Efficacy on Academic achievement in College Students. Journal of College Student Development, 50(3) 337-346. Published by The Johns Hopkins University Press

Verenikina, I., Vialle, W., \& Lysaght, P. (2011). Understanding learning and development. Macksville, NSW: David Barlow Publishing.

WAEC. (2015). Chief $\quad$ Examiner $\quad$ Report. Retrieved from https://www.waecgh.org/Exams/ChiefExaminersReport.aspx

Waters, M. C., Carr, P. J., Kefalas, M. J., \& Holdaway, J. (Eds.) (2011). Coming of age in America: The transition to adulthood in the twenty-first century. Berkley, CA. University of California Press. 